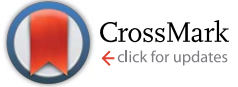

Cite this: RSC Adv., 2016, 6, 8483

Received 2nd December 2015 Accepted 12th January 2016

DOI: $10.1039 / c 5 r a 25686 k$

www.rsc.org/advances

\section{Photoluminescence and afterglow of deep red emitting $\mathrm{SrSC}_{2} \mathrm{O}_{4}: \mathrm{Eu}^{2+}$}

\author{
Matthias Müller, Max-Fabian Volhard and Thomas Jüstel*
}

This work deals with the photoluminescence (PL) properties of $\mathrm{SrSc}_{2} \mathrm{O}_{4}: \mathrm{Eu}^{2+}$ and $\mathrm{SrSc}_{2} \mathrm{O}_{4}: \mathrm{Eu}^{2+}, \mathrm{Dy}^{3+}$. For this purpose a series of powder samples of $\mathrm{SrSc}_{2} \mathrm{O}_{4}$ with various concentrations of $\mathrm{Eu}^{2+}$ and $\mathrm{Dy}^{3+}$ was prepared. The samples were synthesised via a high temperature solid state route. Phase purity was investigated by conducting X-ray powder diffractometry. The PL properties of all prepared samples were elucidated by recording PL and PL excitation spectra. Furthermore, the temperature behaviour of the PL of $\mathrm{SrSc}_{2} \mathrm{O}_{4}: \mathrm{Eu}^{2+}$ was investigated from 100 to $500 \mathrm{~K}$. Diffuse reflectance spectra were recorded to investigate the optical properties of $\mathrm{Eu}^{2+}$ doped $\mathrm{SrSc}_{2} \mathrm{O}_{4}$. Additionally, persistent luminescence of $\mathrm{SrSC}_{2} \mathrm{O}_{4}: \mathrm{Eu}^{2+}$ and $\mathrm{SrSC}_{2} \mathrm{O}_{4}: \mathrm{Eu}^{2+}, \mathrm{Dy}^{3+}$ was investigated. To this end, $\mathrm{PL}$ lifetime measurements were conducted. $\mathrm{SrSC}_{2} \mathrm{O}_{4}: \mathrm{Eu}^{2+}$ shows an emission band in the deep red spectral range. Moreover, it turned out that the red emission of $\mathrm{SrSc}_{2} \mathrm{O}_{4}: \mathrm{Eu}^{2+}$ shows persistent luminescence too.

\section{Introduction}

Today, materials which show red photoluminescence (PL) or persistent luminescence are of great interest for various applications. Their uses as phosphors in light emitting diodes or as fluorescence probes in bio-imaging are only two potential fields of application for these materials. For this reason, many research groups are investigating different host compounds and various dopants to find new red emitting materials. ${ }^{1-3}$ Often, $\mathrm{Eu}^{2+}$ is taken as a dopant to obtain red emission..$^{3,4}$ Since the emission of $\mathrm{Eu}^{2+}$ is due to interconfigurational d-ftransitions, the energy of the emission strongly depends on the host material. Therefore, the emission band of $\mathrm{Eu}^{2+}$ can be shifted from the ultraviolet (UV) to deep red range of the electromagnetic spectrum by changing the chemical environment. ${ }^{5}$

For instance, in a material providing a surrounding with little covalent character like $\mathrm{BaAlF}_{5}$, the $\mathrm{Eu}^{2+}$ emission occurs in the UV range at about $361 \mathrm{~nm}^{6}$ With increasing covalent interaction the emission band of $\mathrm{Eu}^{2+}$ can be located all over the visible spectrum. In $\mathrm{CaAl}_{2} \mathrm{O}_{4}: \mathrm{Eu}^{2+}$ the emission band of $\mathrm{Eu}^{2+}$ is located in the blue spectral range at about $436 \mathrm{~nm} .^{7}$ Green emission of $\mathrm{Eu}^{2+}$ can be observed in oxides and oxy-nitrides like $\mathrm{SrAl}_{2} \mathrm{O}_{4}: \mathrm{Eu}^{2+}\left(\lambda_{\text {em,max }} \approx 512 \mathrm{~nm}\right)$ and $\beta$-SiAlON:Eu ${ }^{2+}\left(\lambda_{\text {em,max }} \approx\right.$ $535 \mathrm{~nm}$ ). Red $5 \mathrm{~d}-4 \mathrm{f}$-emission of $\mathrm{Eu}^{2+}$ is commonly observed in nitrides and sulphides. For example, $\mathrm{Sr}_{2} \mathrm{Si}_{5} \mathrm{~N}_{8}$ : $\mathrm{Eu}^{2+}$ possesses an emission band at about $620 \mathrm{~nm}$. $\mathrm{Eu}^{2+}$ doped sulfides such as $\mathrm{CaS}: \mathrm{Eu}^{2+}$ or SrS: $\mathrm{Eu}^{2+}$ show emission at about 650 and $615 \mathrm{~nm}$, respectively.
So far, not many red emitting luminescent materials on the basis of $\mathrm{Eu}^{2+}$-doped oxides are known and even less showing persistent luminescence in the deep red spectral range. ${ }^{1}$ Most of the red or infrared emitting persistent phosphors are sulphide based compounds doped with lanthanide ions. ${ }^{8}$ Especially in the red region, this group of compounds provides a variety of different emission wavelengths. Unfortunately, such compounds usually are extremely sensitive against moisture and thus chemically unstable. Therefore, further efforts like encapsulation and surface modification are necessary to protect these compounds from degradation. A chemically more stable group of compounds are oxides. Usually, oxides are impervious against moisture. However, most oxides which show red persistent luminescence are doped with $\mathrm{Cr}^{3+}$.

$\mathrm{SrSc}_{2} \mathrm{O}_{4}$ was firstly described and its structure solved by Carter and Feigelson in 1964. ${ }^{9}$ Later Gaume et al. reported on the spectroscopic properties of $\mathrm{Yb}^{3+}$-doped $\mathrm{SrSc}_{2} \mathrm{O}_{4} \cdot{ }^{10}$ To the best of our knowledge there is no report concerning the PL properties of $\mathrm{Eu}^{2+}$ doped $\mathrm{SrSc}_{2} \mathrm{O}_{4}$. Therefore, a series of powder samples of $\mathrm{SrSc}_{2} \mathrm{O}_{4}$ with various contents of $\mathrm{Eu}^{2+}$ and $\mathrm{Dy}^{3+}$ was prepared. $\mathrm{SrSc}_{2} \mathrm{O}_{4}$ crystallizes in the orthorhombic crystal system with space group Pnam. In $\mathrm{SrSc}_{2} \mathrm{O}_{4}$ the $\mathrm{Sr}^{2+}$ ions are surrounded by eight $\mathrm{O}^{2-}$ ions. The ionic radius of 8 -fold coordinated $\mathrm{Sr}^{2+}$ is $1.26 \AA$. 8-Fold coordinated $\mathrm{Eu}^{2+}$ and $\mathrm{Dy}^{3+}$ exhibit ionic radii of $1.25 \AA$ and $1.027 \AA{ }^{11}$ Therefore, it is assumed that the $\mathrm{Eu}^{2+}$ and $\mathrm{Dy}^{3+}$ ions tend to occupy the $\mathrm{Sr}^{2+}$ sites.

\section{Experimental}

The $\mathrm{SrSc}_{2} \mathrm{O}_{4}: \mathrm{Eu}^{2+}$ and $\mathrm{SrSc}_{2} \mathrm{O}_{4}: \mathrm{Eu}^{2+}{ }^{2+} \mathrm{Dy}^{3+}$ samples as investigated in this work were synthesized by high temperature solid state reaction. Therefore, high purity educts $\mathrm{SrCO}_{3}$ (Aldrich, 99.9\%), 
$\mathrm{Sc}_{2} \mathrm{O}_{3}$ (Treibacher Industrie AG, 99.99\%), $\mathrm{Eu}_{2} \mathrm{O}_{3}$ (Treibacher Industrie $\mathrm{AG}, 99.99 \%$ ), and $\mathrm{Dy}_{2} \mathrm{O}_{3}$ (Treibacher Industrie $\mathrm{AG}$, 99.99\%) were weighted in stoichiometric amounts and were thoroughly blended in acetone in an agate mortar. After drying at ambient temperatures, the obtained powder blends were calcined at $1400{ }^{\circ} \mathrm{C}$ for $12 \mathrm{~h}$ in Mo boats in a reducing hydrogen atmosphere (Westfalen, 99.999\%). After calcination, red sinter bodies were obtained which were ground to a fine $\mu$-powder.

Phase purity of the synthesized samples was investigated using X-ray powder diffractometry (XRD). XRD patterns were collected on a Rigaku MiniFlex II diffractometer working in Bragg-Brentano geometry using $\mathrm{Cu} \mathrm{K}_{\alpha}$ radiation. Step width and integration time were set to $0.02^{\circ}$ and $1 \mathrm{~s}$, respectively.

Particle size and morphology were investigated using scanning electron microscopy (SEM). Therefore, the scanning electron microscope Zeiss EVO MA10 equipped with a $\mathrm{LaB}_{6}$-cathode was used. Pressure in the sample chamber was $5 \times 10^{5} \mathrm{~Pa}$ and acceleration voltage was $8 \mathrm{kV}$.

PL as well as PL excitation (PLE) spectra were recorded on an Edinburgh Instruments FSL900 spectrometer equipped with a Xe arc lamp $(450 \mathrm{~W})$ and a cooled $\left(-20^{\circ} \mathrm{C}\right)$ single-photon counting photomultiplier (Hamamatsu R2658P). Obtained PL spectra were corrected by applying a correction file obtained from a tungsten incandescent lamp certified by the National Physics Laboratory U.K.

Persistent luminescence decay (PLD) curves were recorded after exciting the samples for $15 \mathrm{~min}$ with an excitation wavelength of $\lambda_{\text {ex }}=525 \mathrm{~nm}$. Absolute luminance and radiance was measured using the optical power meter 1830-C of Newport Corporation equipped with a Si-detector.

Temperature dependent PL measurements from 100 to $500 \mathrm{~K}$ were performed using the Oxford Instruments cryostat MicrostatN2. Liquid nitrogen was used as a cooling agent. Temperature stabilization time was $60 \mathrm{~s}$ and tolerance was set to $\pm 3 \mathrm{~K}$.

Diffuse reflectance (DR) spectra were recorded on an Edinburgh Instruments FS900 spectrometer equipped with a Xe arc lamp $(450 \mathrm{~W})$, a cooled $\left(-20^{\circ} \mathrm{C}\right)$ single-photon counting photomultiplier (Hamamatsu R928) as well as a Teflon-coated integration sphere. $\mathrm{BaSO}_{4}$ (99.998\%, Sigma-Aldrich) was used as a reflectance standard.

\section{Results and discussion}

The collected XRD patterns as well as the ICDD reference card of $\mathrm{SrSc}_{2} \mathrm{O}_{4}$ are depicted in Fig. 1 for comparison purposes. The diffractograms prove the formation of the orthorhombic $\mathrm{SrSc}_{2} \mathrm{O}_{4}$ phase without any impurity phases. In addition, with increasing $\mathrm{Eu}^{2+}$ doping concentration no significant shift of the reflexes is observed. The diffractograms confirm the used synthesis route for the preparation of $\mathrm{SrSc}_{2} \mathrm{O}_{4}: \mathrm{Eu}^{2+}$.

Morphology of the surface as well as particle size of the prepared samples were investigated by using SEM. Fig. 2 shows the obtained image of $\mathrm{SrSc}_{2} \mathrm{O}_{4}$. The prepared powders of $\mathrm{SrSc}_{2} \mathrm{O}_{4}$ are in micrometer range. Further, the particles are heavily cracked by crushing them in the agate mortar.

Reflectance behaviour of the doped and undoped $\mathrm{SrSc}_{2} \mathrm{O}_{4}$ powder samples was investigated by recording DR spectra.

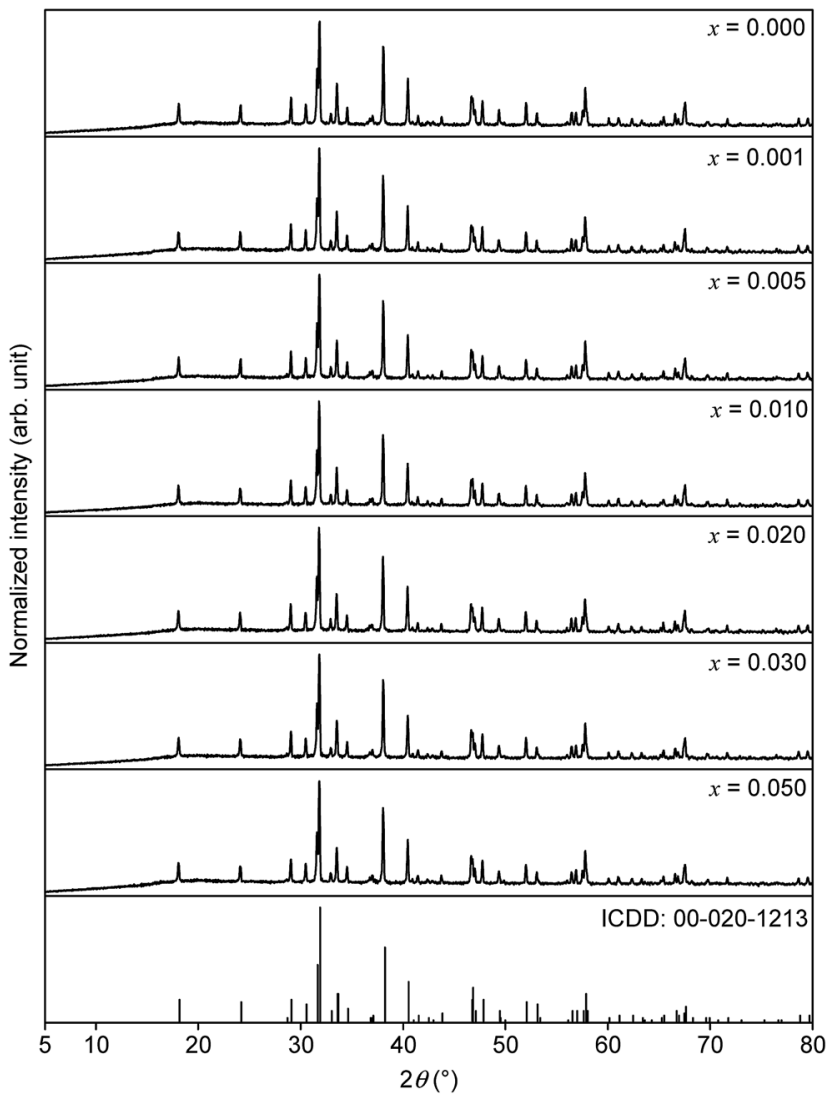

Fig. 1 XRD patterns of $\mathrm{Sr}_{1-x} \mathrm{Eu}_{x} \mathrm{Sc}_{2} \mathrm{O}_{4}$ with various doping concentrations and ICDD reference card of $\mathrm{SrSC}_{2} \mathrm{O}_{4}$.

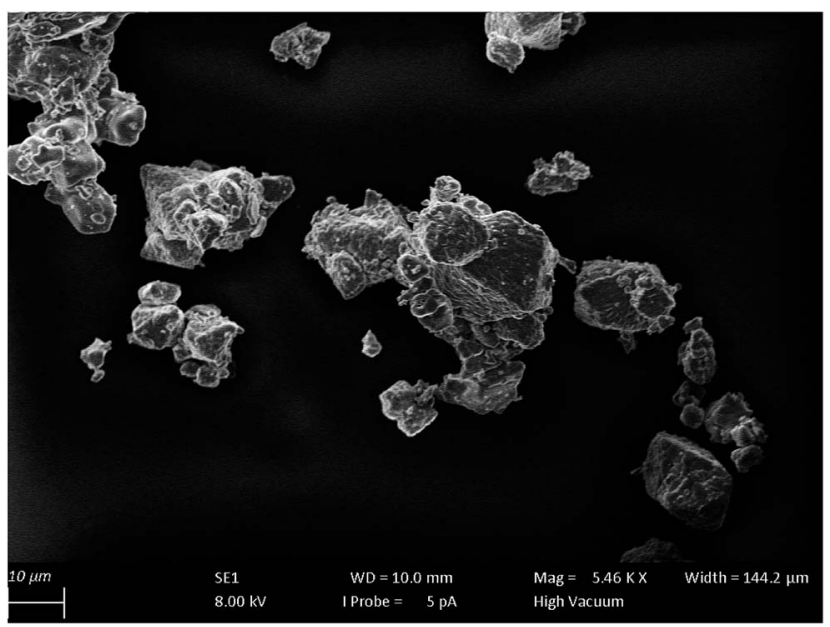

Fig. 2 SEM photograph of $\mathrm{SrSC}_{2} \mathrm{O}_{4}$.

$\mathrm{BaSO}_{4}$ was used as a reflectance standard. The obtained spectra are illustrated in Fig. 3. Undoped $\mathrm{SrSc}_{2} \mathrm{O}_{4}$ shows about $70 \%$ reflectance compared to $\mathrm{BaSO}_{4}$, which is in line with the white to greyish body colour. This greying is ascribed to Mo impurities caused by the Mo foil used during the high temperature annealing. The $\mathrm{Eu}^{2+}$ doped $\mathrm{SrSc}_{2} \mathrm{O}_{4}$ samples show strong absorption bands at about 320 and $475 \mathrm{~nm}$. These bands are 


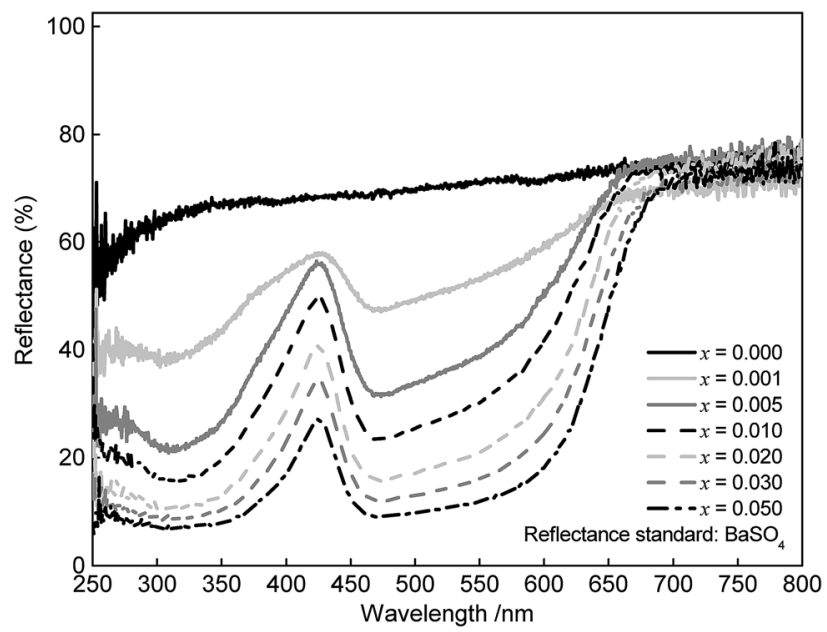

Fig. 3 DR spectra of $\mathrm{Sr}_{1-x} \mathrm{Eu}_{x} \mathrm{Sc}_{2} \mathrm{O}_{4}$ with various doping concentrations.

assigned to transitions from the ${ }^{8} \mathrm{~S}\left([\mathrm{Xe}] 4 \mathrm{f}^{7}\right)$ ground state to the $5 \mathrm{~d}$ multiplet. With increasing $\mathrm{Eu}^{2+}$ concentration this absorption increases and broadens towards the long wavelength range. Therefore, the body colour of $\mathrm{SrSc}_{2} \mathrm{O}_{4}: \mathrm{Eu}^{2+}$ is shifted from light pink to red violet.

PL as well as PLE spectra of $\mathrm{Sr}_{0.98} \mathrm{Eu}_{0.02} \mathrm{Sc}_{2} \mathrm{O}_{4}$ are depicted in Fig. 4. The PLE spectrum was recorded monitoring the $\mathrm{Eu}^{2+}$ emission at $\lambda_{\mathrm{em}}=720 \mathrm{~nm}$. The obtained PLE spectrum shows a broad band which consists of various unresolved bands. This band originates from the transition of the ${ }^{8} \mathrm{~S}$ ground state to the excited states ${ }^{6} \mathrm{P}$ and ${ }^{8} \mathrm{P}\left([\mathrm{Xe}] 4 \mathrm{f}^{6} 5 \mathrm{~d}^{1}\right) .{ }^{12} \mathrm{PL}$ of $\mathrm{SrSc}_{2} \mathrm{O}_{4}: \mathrm{Eu}^{2+}$ was measured upon excitation of $\lambda_{\mathrm{ex}}=525 \mathrm{~nm}$. The obtained spectrum shows a broad band in the deep red range of the visible spectrum. This emission band ranges from about 595 to $840 \mathrm{~nm}$ with a maximum at about $687 \mathrm{~nm}$ and a full width half maximum of about $103 \mathrm{~nm}\left(2098 \mathrm{~cm}^{-1}\right)$. Hence, the PL maximum of $\mathrm{SrSc}_{2} \mathrm{O}_{4}: \mathrm{Eu}^{2+}$ is located in the first bio-imaging window.

The PLE spectra obtained from $\mathrm{Sr}_{1-x} \mathrm{Eu}_{x} \mathrm{Sc}_{2} \mathrm{O}_{4}$ with $x=0.02$, 0.03 , and 0.05 are depicted in Fig. 5. The PLE maximum shifts towards longer wavelengths with increasing $\mathrm{Eu}^{2+}$ concentration.

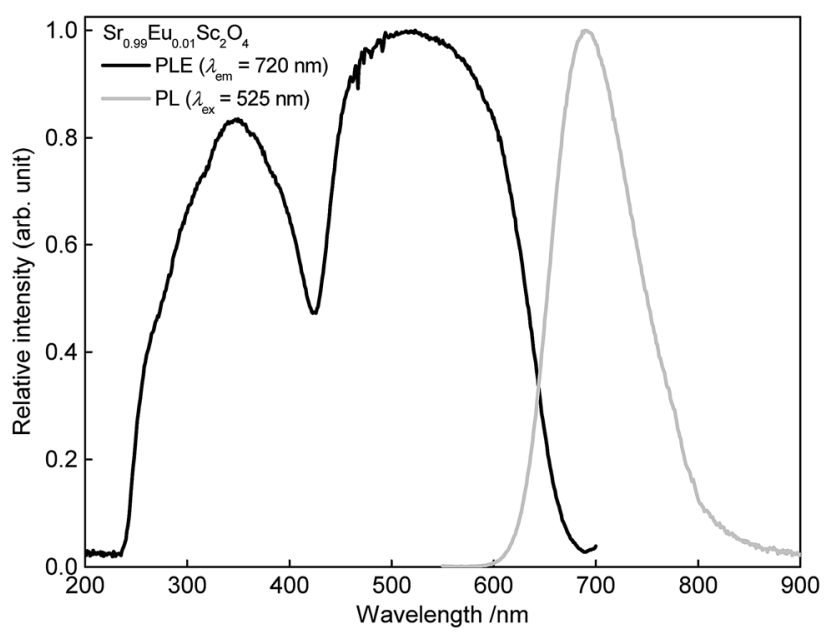

Fig. 4 Room temperature PL and PLE spectra of $\mathrm{Sr}_{0.98} \mathrm{Eu}_{0.02} \mathrm{Sc}_{2} \mathrm{O}_{4}$.

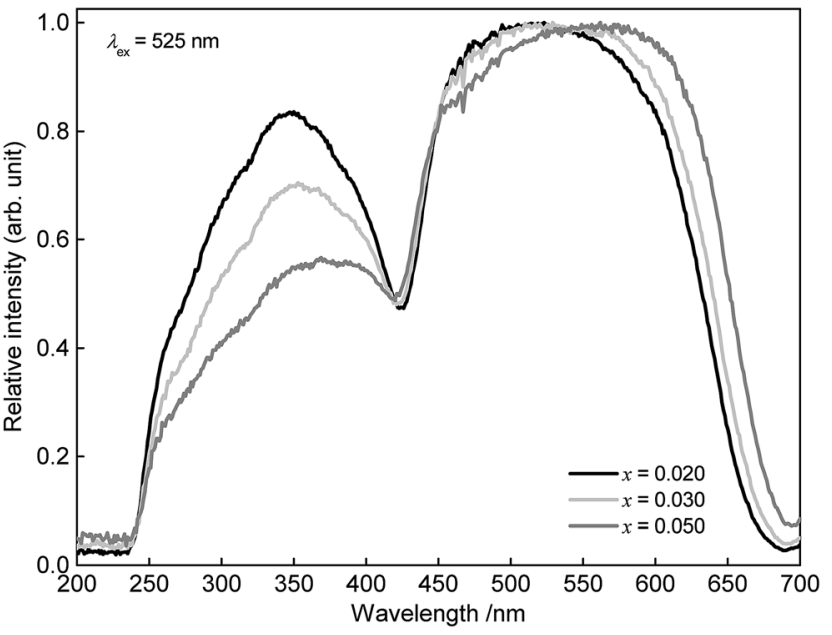

Fig. 5 Room temperature PLE spectra of $\mathrm{Sr}_{1-x} \mathrm{Eu}_{x} \mathrm{Sc}_{2} \mathrm{O}_{4}$ with various $\mathrm{Eu}^{2+}$ concentrations.

In addition to that, the PLE spectra broaden with increasing $\mathrm{Eu}^{2+}$ concentration. The shift of the excitation maximum is mainly ascribed to a change in covalency. This is verified by calculating the centroid wavenumber of the excitation bands. The results are summarized in Table 1. With increasing $\mathrm{Eu}^{2+}$ concentration the calculated energy of the centroid wavenumbers decrease. This observation reflects an increase in the covalency of the bonds of $\mathrm{SrSc}_{2} \mathrm{O}_{4}: \mathrm{Eu}^{2+}$ and is attributed to the higher alkalinity of $\mathrm{Eu}^{2+}$ compared to $\mathrm{Sr}^{2+}$. To investigate the broadening of the excitation band in more detail, the crystal field splitting of the d-orbitals of $\mathrm{Eu}^{2+}$ was calculated (see Table 1). With increasing $\mathrm{Eu}^{2+}$ concentration crystal field splitting increases, too. Since $\mathrm{Eu}^{2+}$ is slightly smaller than $\mathrm{Sr}^{2+}$, the incorporation of $\mathrm{Eu}^{2+}$ into $\mathrm{SrSc}_{2} \mathrm{O}_{4}$ leads to a smaller $\mathrm{Sr}$ site and thus to higher crystal field splitting of the d-orbitals.

PL spectra of $\mathrm{Sr}_{1-x} \mathrm{Eu}_{x} \mathrm{Sc}_{2} \mathrm{O}_{4}$ with $x=0.001,0.005,0.010,0.020$, 0.030 , and 0.050 are illustrated in Fig. 6 . The spectra were recorded using an excitation wavelength of $\lambda_{\mathrm{ex}}=525 \mathrm{~nm}$. No $\mathrm{Eu}^{3+}$ emission was observed. Therefore, it is assumed that the concentration of $\mathrm{Eu}^{2+}$ corresponds to the amount which was weighed out. With increasing $\mathrm{Eu}^{2+}$ concentration the PL maximum shifts from 688 to $702 \mathrm{~nm}$. In addition to that, with increasing doping concentration the PL intensity of $\mathrm{Sr}_{1-x} \mathrm{Eu}_{x} \mathrm{Sc}_{2} \mathrm{O}_{4}$ increases up to an $\mathrm{Eu}^{2+}$ content of $x=0.005$. At higher concentrations the PL intensity decreases due to concentration quenching (inset Fig. 6).

Table 1 Excitation bands, crystal field splitting, and centroid shift of $\mathrm{Sr}_{1-x} \mathrm{Eu}_{x} \mathrm{Sc}_{2} \mathrm{O}_{4}$ with various $\mathrm{Eu}^{2+}$ concentrations

\begin{tabular}{llll}
\hline $\begin{array}{l}\text { Sample } \\
(x)\end{array}$ & $\begin{array}{l}\lambda_{\text {ex }} \text { range } \\
(\mathrm{nm})\end{array}$ & $\begin{array}{l}\text { Crystal field } \\
\text { splitting }\left(\mathrm{cm}^{-1}\right)\end{array}$ & $\begin{array}{l}\text { Centroid } \\
\text { wavenumber }\left(\mathrm{cm}^{-1}\right)\end{array}$ \\
\hline 0.02 & $238 \cdots 697$ & 27670 & 26596 \\
0.03 & $237 \cdots 689$ & 27680 & 25381 \\
0.05 & $235 \cdots 685$ & 27954 & 23810
\end{tabular}




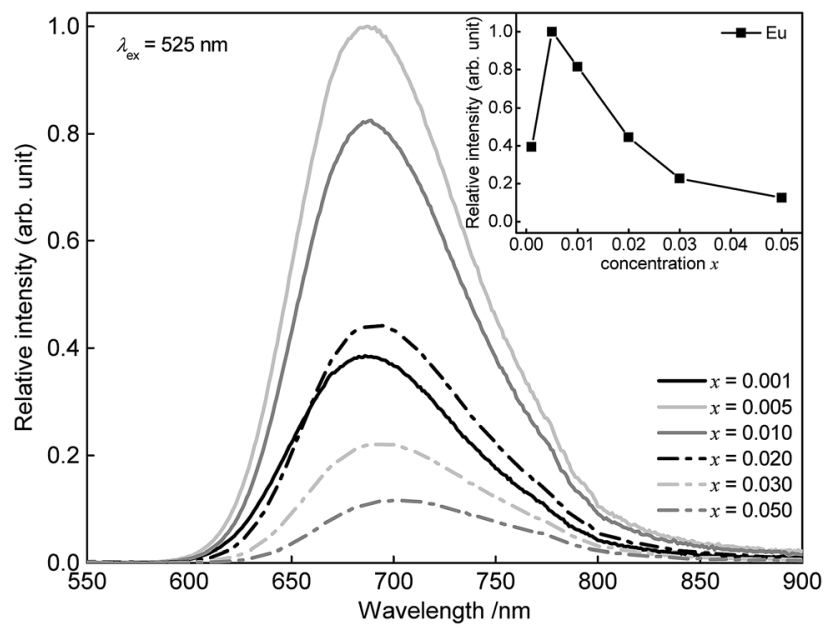

Fig. $6 \mathrm{PL}$ spectra of $\mathrm{Sr}_{1-x} \mathrm{Eu}_{x} \mathrm{Sc}_{2} \mathrm{O}_{4}$ with various $\mathrm{Eu}^{2+}$ concentrations. Inset: integrated PL intensity in dependence of the $\mathrm{Eu}^{2+}$ concentration.

To investigate the mechanism of the energy transfer responsible for concentration quenching, van Uitert's approach was applied: $:^{13}$

$$
\frac{I}{x}=\frac{k}{1+A x^{\frac{\theta}{3}}}
$$

here, $I$ is the intensity, $k$ as well as $A$ are constants, and $x$ is the concentration of $\mathrm{Eu}^{2+} . \theta=3$ corresponds to exchange interaction whereas $\theta=6,8$, and 10 corresponds to dipole-dipole, dipole-quadrupole, and quadrupole-quadrupole interaction, respectively. Fig. 7 depicts the experimental data and the fitting curves. The best fitting is obtained for $\theta=6$ indicating that the mechanism of concentration quenching occurs via dipoledipole interaction. This result is quite reasonable since the transitions of excitation and emission of $\mathrm{Eu}^{2+}$ are quantum mechanically allowed.

Furthermore, the critical distance $R_{\mathrm{c}}$ between the $\mathrm{Eu}^{2+}$ ions was calculated. $R_{\mathrm{c}}$ is defined as the distance, at which the probability of energy transfer equals the probability of radiative

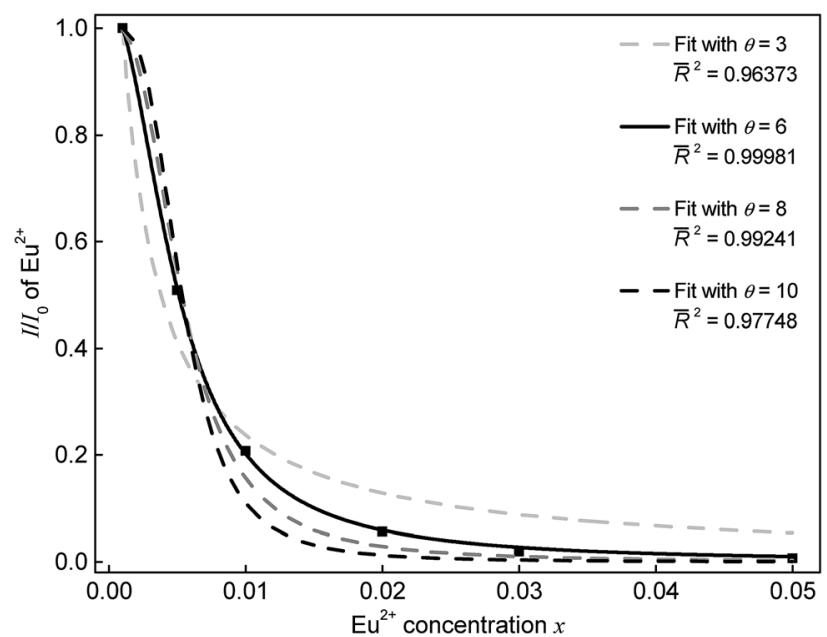

Fig. 7 Dependence of $/ / I_{0}$ on the $\mathrm{Eu}^{2+}$ concentration. transition. To estimate the critical distance $R_{\mathrm{c}}$ between $\mathrm{Eu}^{2+}$ ions in $\mathrm{SrSc}_{2} \mathrm{O}_{4}$ : $\mathrm{Eu}^{2+}$ Dexter's formula for dipole-dipole interaction can be used: ${ }^{14}$

$$
R_{\mathrm{c}}{ }^{6}=0.63 \times 10^{28} \frac{Q_{\mathrm{A}}}{E^{4}} \int F_{\mathrm{S}}(E) F_{\mathrm{A}}(E) \mathrm{d} E
$$

In this equation $Q_{\mathrm{A}}$ is the absorption cross section of $\mathrm{Eu}^{2+}$ and $E$ is the energy of maximum spectral overlap. $\int F_{\mathrm{S}}(E) F_{\mathrm{A}}(E) \mathrm{d} E$ represents the spectral overlap of the normalized PL $\left(F_{\mathrm{S}}(E)\right)$ and $\operatorname{PLE}\left(F_{\mathrm{A}}(E)\right)$ spectrum of $\mathrm{Eu}^{2+}$. $Q_{\mathrm{A}}$ is $4.8 \times 10^{-16} f_{\mathrm{d}}$. Here, $f_{\mathrm{d}}$ is the oscillator strength of the electronic transitions of $\mathrm{Eu}^{2+}$ and was taken as 0.02 . The spectral overlap integral was calculated to be $0.03 \mathrm{eV}^{-1}$. Plugging these values into eqn (2) $R_{\mathrm{c}}$ is calculated to be $20.3 \AA$.

In order to examine the temperature behaviour of the PL of $\mathrm{SrSc}_{2} \mathrm{O}_{4}: \mathrm{Eu}^{2+}$ PL spectra were recorded from 100 to $500 \mathrm{~K}$. The resulting spectra are illustrated in Fig. 8. With increasing temperature the PL intensity gradually decreases. Moreover, the emission maximum shifts from 692 to $680 \mathrm{~nm}$. Due to extending equilibrium distance between $\mathrm{Eu}^{2+}$ and its surrounding oxygen ligands with increasing temperature, crystal field splitting of the d-orbitals of $\mathrm{Eu}^{2+}$ decreases. As a consequence, the energetic distance between the $\mathrm{d}$ and f-orbitals increases and the emission maximum is shifted towards higher energy. The inset of Fig. 8 depicts the integrated PL intensity of the investigated sample. Fitting these data points with a Fermi-Dirac distribution yields the activation energy $E_{\mathrm{A}}$ for thermal quenching.

$$
I(T)=\frac{I_{0}}{1+B \mathrm{e}^{\frac{-E_{\mathrm{A}}}{k T}}}
$$

In eqn (3) $I(T)$ is the PL intensity at a certain temperature and $I_{0}$ is the PL intensity at zero kelvin. $B$ is the frequency factor for thermal quenching, $k=8.617 \times 10^{-5} \mathrm{eV} \mathrm{K}^{-1}$ is the Boltzmann constant, and $T$ is the temperature. Parameters $I_{0}$ and $B$ were derived from the fitting function and are about 0.97 and 2945,

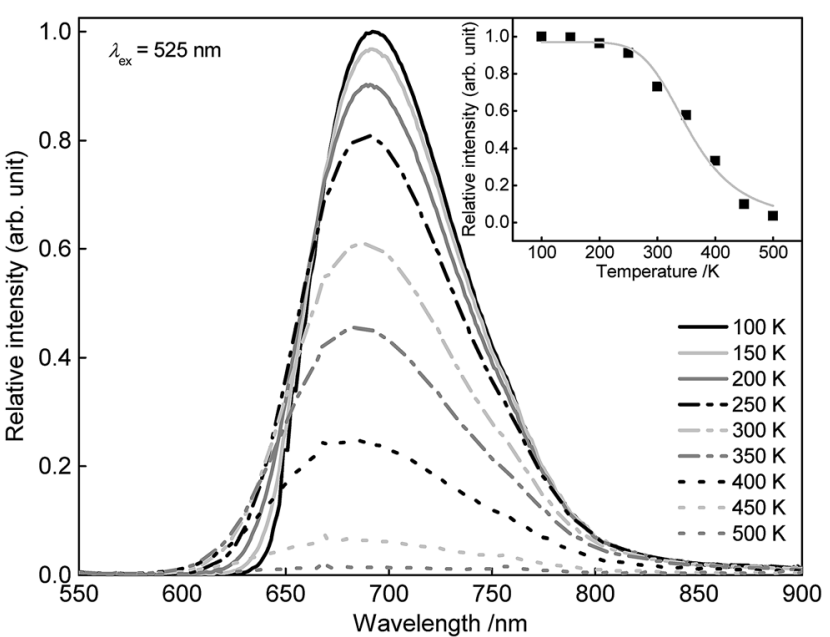

Fig. $8 \mathrm{PL}$ spectra of $\mathrm{Sr}_{0.995} \mathrm{Eu}_{0.005} \mathrm{Sc}_{2} \mathrm{O}_{4}$ from 100 to $500 \mathrm{~K}$. Inset: integrated $\mathrm{PL}$ intensity in dependence of the temperature. 
respectively. From this $E_{\mathrm{A}}$ was calculated to be $0.25 \mathrm{eV}$. By applying $E_{\mathrm{A}}$ to the following formula, $T_{1 / 2}$ can be calculated:

$$
T_{1 / 2}=\frac{-E_{\mathrm{A}}}{k \ln \left(\frac{1}{B}\right)}
$$

$T_{1 / 2}$ is the temperature where PL intensity of a luminescent centre decreases to one-half of its maximal intensity. For the herein investigated $\mathrm{Sr}_{0.995} \mathrm{Eu}_{0.005} \mathrm{Sc}_{2} \mathrm{O}_{4}$ sample $T_{1 / 2}$ was calculated to be $357 \mathrm{~K}$.

To investigate the persistent luminescence properties of $\mathrm{Eu}^{2+}$ doped $\mathrm{SrSc}_{2} \mathrm{O}_{4}$, luminescent lifetime measurements were conducted. For that purpose, the investigated samples were charged for $15 \mathrm{~min}$ with an excitation wavelength of $\lambda_{\text {ex }}=525$ nm. Fig. 9 shows the obtained PLD curves of $\mathrm{Sr}_{1-x} \mathrm{Eu}_{x} \mathrm{Sc}_{2} \mathrm{O}_{4}$ with $x=0.001,0.005$, and 0.010 . The longest afterglow duration was found for $\mathrm{Sr}_{0.999} \mathrm{Eu}_{0.001} \mathrm{Sc}_{2} \mathrm{O}_{4}$. The corresponding PLD curve can be best fitted with the following equation:

$$
I=A_{1} \mathrm{e}^{\frac{-t}{\tau_{1}}}+A_{2} \mathrm{e}^{\frac{-t}{\tau_{2}}}+A_{3} \mathrm{e}^{\frac{-t}{\tau_{3}}}+A_{4} \mathrm{e}^{\frac{-t}{\tau_{4}}}
$$

here, $I$ is the PL intensity, $A_{1}, A_{2}, A_{3}$, and $A_{4}$ are fitting parameters, and $t$ is the time. $\tau_{1}, \tau_{2}, \tau_{3}$, and $\tau_{4}$ are the partial luminescence lifetimes of the exponential components. The average luminescence lifetime can be obtained using eqn (6):

$$
\tau=\frac{A_{1} \tau_{1}^{2}+A_{2} \tau_{2}^{2}+A_{3} \tau_{3}^{2} A_{4} \tau_{4}^{2}}{A_{1} \tau_{1}+A_{2} \tau_{2}+A_{3} \tau_{3}+A_{4} \tau_{4}}
$$

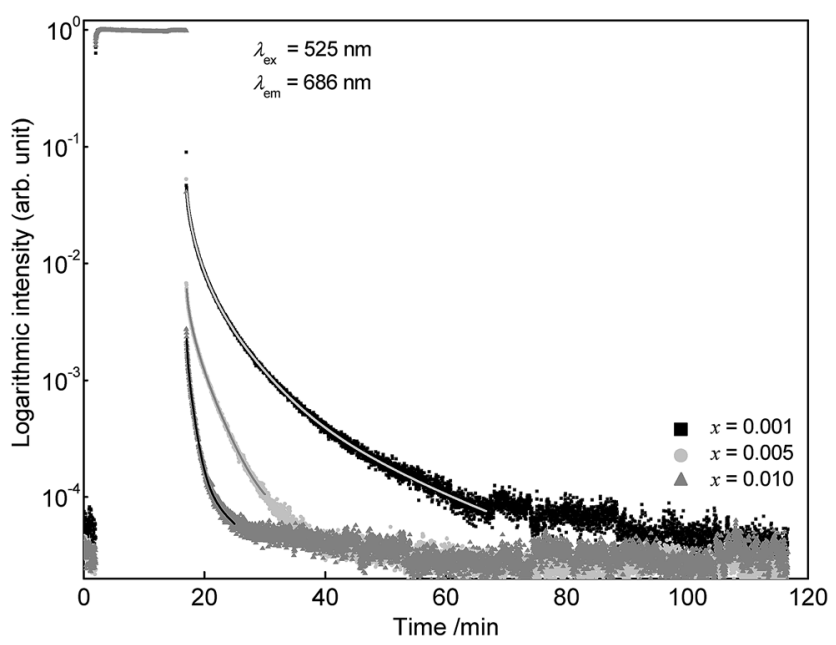

Fig. 9 PLD curves of $\mathrm{Sr}_{1-x} \mathrm{Eu}_{x} \mathrm{Sc}_{2} \mathrm{O}_{4}$ with various doping concentrations.
Partial lifetimes and their corresponding emission fractions as well as the calculated average lifetime $\tau$ are summarized in Table 2. With increasing $\mathrm{Eu}^{2+}$ content the PL lifetime of $\mathrm{SrSc}_{2} \mathrm{O}_{4}: \mathrm{Eu}^{2+}$ decreases and the PLD curve becomes tri-exponential.

It is well known that additional incorporation of $\mathrm{Dy}^{3+}$ into $\mathrm{Eu}^{2+}$ doped materials can lead to long lasting persistent phosphors. ${ }^{15}$ In order to investigate the influence of $\mathrm{Dy}^{3+} \mathrm{Co}^{-}$ doping on the afterglow duration, additional luminescence lifetime measurements were performed on $\mathrm{Sr}_{0.998} \mathrm{Eu}_{0.001}$ $\mathrm{Dy}_{0.001} \mathrm{Sc}_{2} \mathrm{O}_{4}$ and $\mathrm{Sr}_{0.994} \mathrm{Eu}_{0.001} \mathrm{Dy}_{0.005} \mathrm{Sc}_{2} \mathrm{O}_{4}$. Fig. 10 illustrates the PLD curves of co-doped $\mathrm{SrSc}_{2} \mathrm{O}_{4}: \mathrm{Eu}^{2+}, \mathrm{Dy}^{3+}$. Analogous to $\mathrm{Eu}^{2+}$, with increasing $\mathrm{Dy}^{3+}$ concentration the afterglow duration decreases. Another possibility to enhance the afterglow duration of $\mathrm{SrSc}_{2} \mathrm{O}_{4}: \mathrm{Eu}^{2+}$ could be co-doping with $\mathrm{Cr}^{3+} \cdot{ }^{16}$ Further experiments should be performed to investigate the influence of $\mathrm{Cr}^{3+}$ co-doping on the persistent luminescence properties of $\mathrm{SrSc}_{2} \mathrm{O}_{4}: \mathrm{Eu}^{2+}$.

Fig. 11a depicts the luminance in dependence of the time. For comparison the solid line visualises the luminance value $0.32 \mathrm{mcd}$ $\times \mathrm{m}^{-2}$ which is the minimum value commonly used for safety signage. ${ }^{17}$ The dashed line illustrates the limit of the sensitivity of the dark-adapted eye. For the $\mathrm{Sr}_{0.999} \mathrm{Eu}_{0.001} \mathrm{Sc}_{2} \mathrm{O}_{4}$ sample $0.32 \mathrm{mcd}$ $\times \mathrm{m}^{-2}$ is reached after about $6 \mathrm{~min}$. Absolute radiance is plotted in Fig. 11b. The absolute radiance values obtained after charging the sample for $15 \mathrm{~min}$ are considerably smaller compared to other deep red emitting persistent phosphors. ${ }^{18}$

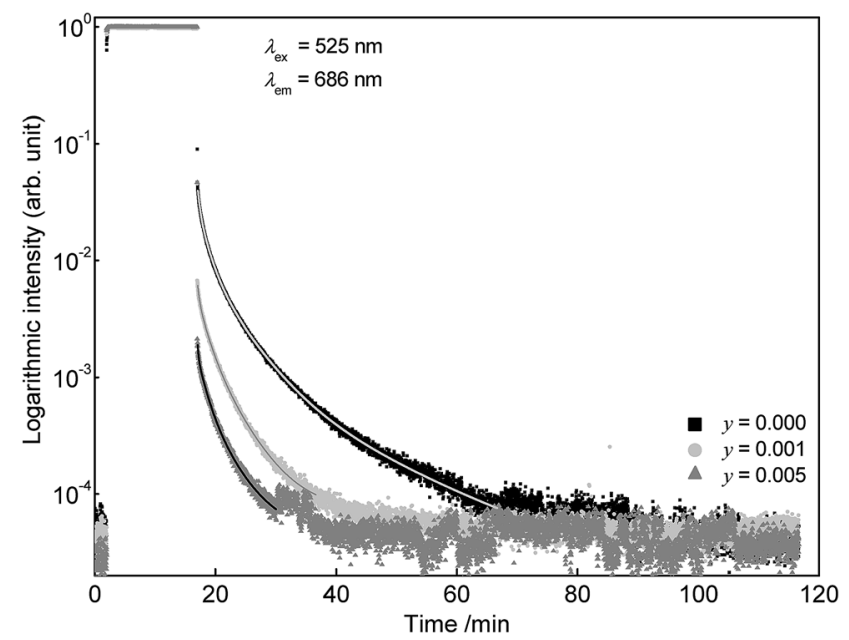

Fig. 10 PLD curves of $\mathrm{Sr}_{0.999-y} \mathrm{Eu}_{0.001} \mathrm{Dy}_{y} \mathrm{Sc}_{2} \mathrm{O}_{4}$ with different concentrations of $\mathrm{Dy}^{3+}$.

Table 2 Persistent luminescence lifetimes $\tau$ as well as partial lifetimes $\tau_{1}, \tau_{2}, \tau_{3}$, and $\tau_{4}$ and the emission fractions frac $c_{1}$, frac frac $_{3}$, and frac f $_{4}$ $\mathrm{Eu}^{2+}$ in $\mathrm{Sr}_{1-x} \mathrm{Eu}_{x} \mathrm{Sc}_{2} \mathrm{O}_{4}$ and $\mathrm{Sr}_{1-x-y} \mathrm{Eu}_{x} \mathrm{Dy}_{y} \mathrm{Sc}_{2} \mathrm{O}_{4}$

\begin{tabular}{lrllllllr}
\hline Sample $(x, y)$ & $\tau_{1}(\mathrm{~s})$ & $\operatorname{frac}_{1}(\%)$ & $\tau_{2}(\mathrm{~s})$ & $\operatorname{frac}_{2}(\%)$ & $\tau_{3}(\mathrm{~s})$ & frac $_{3}(\%)$ & $\tau_{4}(\mathrm{~s})$ & frac $_{4}(\%)$ \\
\hline $0.001,0.000$ & 21.7 & 4.8 & 88.3 & 27.4 & 293.6 & 47.3 & 1007.4 & 20.6 \\
$0.005,0.000$ & 10.4 & 2.3 & 57.9 & 18.7 & 193.6 & 79.0 & 371 \\
$0.010,0.000$ & 9.6 & 6.2 & 56.1 & 59.7 & 283.8 & 34.1 & 164 \\
$0.001,0.001$ & 16.2 & 3 & 93.7 & 32.0 & 271.1 & 65.0 & 131 \\
$0.001,0.005$ & 9.2 & 2.0 & 84.8 & 32.2 & 257.0 & 65.9 & 207 \\
& & & & & & & 197
\end{tabular}



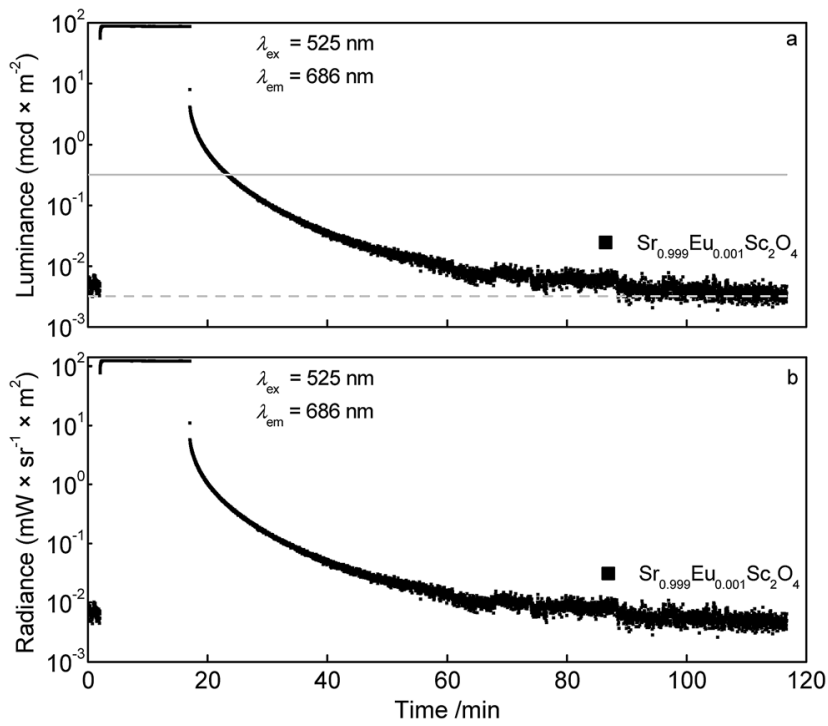

Fig. 11 Persistent luminescence curves of $\mathrm{Sr}_{0.999} \mathrm{Eu}_{0.001} \mathrm{Sc}_{2} \mathrm{O}_{4}$ : luminance (a) and radiance (b) of the $\mathrm{Eu}^{2+}$ emission.

\section{Conclusions}

$\mathrm{SrSc}_{2} \mathrm{O}_{4}: \mathrm{Eu}^{2+}$ powder samples were prepared and its PL properties were investigated, also time and temperature dependent. $\mathrm{SrSc}_{2}$ $\mathrm{O}_{4}: \mathrm{Eu}^{2+}$ shows a broad emission band in the deep red region of the spectrum with a maximum at about $687 \mathrm{~nm}$. This deep red lying emission band is quite rare for oxidic host materials doped with $\mathrm{Eu}^{2+}$. $^{1}$ Further, no $\mathrm{Eu}^{3+}$ emission was observed. The highest $\mathrm{PL}$ intensity was found for a $\mathrm{Eu}^{2+}$ concentration of $x=0.005$. At a higher $\mathrm{Eu}^{2+}$ concentration the PL intensity decreases due to concentration quenching caused by energy transfer between $\mathrm{Eu}^{2+}$ ions, likely resulting in energy migration to defect states. It turned out that in $\mathrm{SrSc}_{2} \mathrm{O}_{4}: \mathrm{Eu}^{2+}$ energy transfer between $\mathrm{Eu}^{2+}$ ions is of a resonance type and occurs via dipole-dipole interaction. The critical distance $R_{\mathrm{c}}$ was calculated to be about $20.3 \AA$. Temperature dependent PL measurements revealed a $T_{1 / 2}$ value of $357 \mathrm{~K}$. Additionally, it was found that $\mathrm{SrSc}_{2} \mathrm{O}_{4}: \mathrm{Eu}^{2+}$ shows deep red persistent luminescence after charging it with an excitation wavelength of $\lambda_{\mathrm{ex}}=525 \mathrm{~nm}$. The longest afterglow duration was found for the sample $\mathrm{Sr}_{0.999} \mathrm{Eu}_{0.001} \mathrm{Sc}_{2} \mathrm{O}_{4}$. This sample reaches the value of $0.32 \mathrm{mcd} \times \mathrm{m}^{-2}$ after about $6 \mathrm{~min}$ what is considerably shorter than for comparable materials. ${ }^{18}$ No increase in afterglow duration could be observed if $\mathrm{SrSc}_{2} \mathrm{O}_{4}: \mathrm{Eu}^{2+}$ was additionally doped by $\mathrm{Dy}^{3+}$. For this reason, it would be worth the effort to try to increase the afterglow duration by doping with additional ions like $\mathrm{Cr}^{3+}$.

\section{Acknowledgements}

The authors are grateful to Merck KGaA Darmstadt, Germany for generous financial support.

\section{References}

1 D. Deng, H. Yu, Y. Li, Y. Hua, G. Jia, S. Zhao, H. Wang, L. Huang, Y. Li, C. Li and S. Xu, J. Mater. Chem. C, 2013, 1, 3194.

2 (a) K. Song, J. Zhang, Y. Liu, C. Zhang, J. Jiang, H. Jiang and H.-B. Qin, J. Phys. Chem. C, 2015, 119, 24558-24563; (b) R. Yu, N. Xue, T. Wang, Z. Zhao, J. Wang, Z. Hei, M. Li, H. Mi Noh and J. Hyun Jeong, Ceram. Int., 2015, 41, 6030-6036.

3 P. Pust, V. Weiler, C. Hecht, A. Tücks, A. S. Wochnik, A.-K. Henß, D. Wiechert, C. Scheu, P. J. Schmidt and W. Schnick, Nat. Mater., 2014, 13, 891-896.

4 (a) R.-J. Xie, N. Hirosaki, T. Suehiro, F.-F. Xu and M. Mitomo, Chem. Mater., 2006, 18, 5578-5583; (b) S. Tezuka, Y. Sato, T. Komukai, Y. Takatsuka, H. Kato and M. Kakihana, Appl. Phys. Express, 2013, 6, 72101.

5 (a) S. H. M. Poort, H. M. Reijnhoudt, H. O. T. van der Kuip and G. Blasse, J. Alloys Compd., 1996, 241, 75-81; (b) S. H. M. Poort and G. Blasse, J. Lumin., 1997, 72-74, 247-249. 6 W. Zhang, R. Hua, T. Liu, J. Zhao, L. Na and B. Chen, Mater. Res. Bull., 2014, 60, 247-251.

7 (a) C. Chang, J. Xu, L. Jiang, D. Mao and W. Ying, Mater. Chem. Phys., 2006, 98, 509-513; (b) B. Zhang, C. Zhao and D. Chen, Luminescence, 2010, 25, 25-29.

8 (a) J. Zhang, Y.-L. Liu and S.-q. Man, J. Lumin., 2006, 117, 141-146; (b) X. Duane, S. Huang, F. You and K. Kang, J. Rare Earths, 2009, 27, 43-46; (c) S. K. Singh, RSC Adv., 2014, 4, 58674-58698.

9 J. R. Carter and R. S. Feigelson, J. Am. Ceram. Soc., 1964, 47, 141-144.

10 R. Gaume, B. Viana, J. Derouet and D. Vivien, Opt. Mater., 2003, 22, 107-115.

11 R. D. Shannon, Acta Crystallogr., Sect. A: Cryst. Phys., Diffr., Theor. Gen. Crystallogr., 1976, 32, 751-767.

12 (a) G. Blasse, Phys. Status Solidi B, 1973, 55, K131-K134; (b) G. Blasse and B. C. Grabmaier, Luminescent Materials, Springer-Verlag, Berlin/Heidelberg, 1st edn, 1994.

13 L. G. van Uitert, J. Electrochem. Soc., 1967, 114, 1048.

14 (a) D. L. Dexter, J. Chem. Phys., 1953, 21, 836; (b) G. Blasse, Philips Res. Rep., 1969, 24, 131-144.

15 (a) I. P. Sahu, D. P. Bisen, N. Brahme and M. Ganjir, Luminescence, 2015, 30, 1318-1325; (b) B. K. Gupta, A. Kumar, P. Kumar, J. Dwivedi, G. N. Pandey and G. Kedawat, J. Appl. Phys., 2015, 117, 243104; (c) P. Wang, X. Xu, D. Zhou, X. Yu and J. Qiu, Inorg. Chem., 2015, 54, 1690-1697.

16 (a) H. Ryu and K. S. Bartwal, J. Alloys Compd., 2008, 464, 317321; (b) J. Ueda, K. Kuroishi and S. Tanabe, Appl. Phys. Express, 2014, 7, 62201.

17 K. van den Eeckhout, D. Poelman and P. Smet, Materials, 2013, 6, 2789-2818.

18 (a) J. Xu, S. Tanabe, A. D. Sontakke and J. Ueda, Appl. Phys. Lett., 2015, 107, 81903; (b) Y. Zhuang, J. Ueda and S. Tanabe, Appl. Phys. Express, 2013, 6, 52602. 